\title{
OTRA VEZ TRESGUERRAS
}

\author{
P O R
}

\section{FRANCISCO DE LA MAZA}

\section{UNA SILLERÍA DE CORO}

T REsGuerRas, después de muerto, sigue desconcertando y dando sorpresas a los que de él nos hemos ocupado. Recién salidos de la imprenta sus Ocios Literarios, ${ }^{1}$ en cuyo prólogo decía yo que el artista celayense vivia en Querétaro en 1796 y que "lo único que podemos asegurar es que habia sido llamado por el Ayuntamiento para construir una fuente, la que sería después de Neptuno", supe que algo más hacía en Querétaro y precisamente en 1796.

En efecto, conversando un dia con Alfredo Bishop, arquitecto de la Dirección de Monumentos Coloniales, me dijo que había visto la firma de Tresguerras en la sillería del coro de San Francisco. Nunca se había dicho cosa semejante y los queretanos, al parecer, lo ignoran todavía. Y es que, en verdad, es difícil encontrar esa firma. Pero allí está, en el primer tablero que inicia la sillería franciscana.

Un día de mayo de 1962 fui a comprobar el aserto de Bishop en compañia de Víctor Manuel Villegas. Mientras yo contemplaba la fecha, en el último tablero, Villegas leía la firma. Una obra más habrí que añadir a la fecunda labor de Tresguerras.

Conocida es la afirmación de su Carta Autobiográfica en que dice

1 En Estudios y Fuentes del Arte en México, vol. xir, cdición, prólogo y notas de Francisco de la Maza. México, 1962. 
que en su juventud había sido "carpintero y tallista", pero nada nos constaba de esto. Ahora sí, con la sillería de San Francisco.

En un papel enrollado que muerde un perro, ese mismo perro que también dibujó en los Ocios, dice: TRESGUERRAS ft (fecit). Y en una ménsula, en el tablero final, en forma mucho más visible: AÑO DE 1796. Más claro, ni el agua.

Es una elegante y severa sillería cuyos asientos se dividen por medio de modillones que son divisorios y ornamentales, pero no funcionales, pues no se pueden recargar en ellos los codos. Sobre las sillas superiores van tableros. Unos son cuadrados y tuvieron medallones, de los cuales no existe ni uno solo. Lo más probable es que no llegaron a ponerse. Otros son rectangulares y en ello sí se conservan los relieves que, en parte de la propia mano de Tresguerras y todos bajo su dirección, llevan unos finos y preciosamente tallados adornos de hojas, flores y lazos en cuyo centro van instrumentos musicales, salvo uno en que va un incensario. Las pilastrillas que dividen los tableros son de orden jónico y en las esquinas hay unos nichos con sus conchas y columnas exentas. Por allí andan, bajo estos nichos, tiradas en el suelo, unas bonitas pilastrillas estípites, que pueden ser de la antigua sillería churrigueresca.

La diferencia con las sillerias de coro antiguas, del románico al barroco, es evidente. Aquí estamos, no ante un religioso coro con santos o símbolos en sus respaldos, sino ante un elegante mueble francés, nada religioso, sino puramente suntuario. El "ilustrado" neoclásico cumplia con su sentido histórico.

\section{Addenda a los Ocios}

Otra falta, casi grave, fue cometida en la publicación de los Ocios. Tratándose de Tresguerras no me da pena confesarla pues parecen fatalidades que él mismo provoca desde su bella tumba de Celaya. El Br. José Rojas Garcidueñas se acordó y me recordó que, en un estudio de Manuel Toussaint sobre fray Manuel de Navarrete, se hablaba de algunos de los personajes principales de los Ocios. Así como, según dijo una vez don Alfonso Reyes, que él "tenía memoria de colodión", por lo firme, segura y pegadiza, yo la tengo de agua corriente y olvidé ese estudio. Es el llamado Nuevos Aspectos en la biografia de fray Manuel Navarrete, ${ }^{1}$ en el que Toussaint translada unas notas, a los Entreteni-

1 En la Revista de Literatura Mexicana, año 1, No 2, México, octubre-diciembre (le 1940, pp. 226-234. 
mientos Poéticos de Navarrete, manuscrito que él posefa. Las notas al pie que se refieren a los personajes de los Ocios son las siguientes:

(3) En las Sátiras contra Poetastros \& ${ }^{a}$ (T. II. 139). Uno de ellos fue don Mariano Romero (que destripó en el último año (1791, o 92), el primer curso de mi Padrino y Maestro don Jacobo Pardo y Pereda, catedrático de Filosofía y Rector del Colegio de San Xavier). Romero era estropeado de un pie; poseía algunas habilidades entre ellas la de jugar perfectamente a las Damas. (Estudió Matemáticas y murió en México no sé cuándo).

(4) El Monigote satirizado, don Felipe Suasnávar, no es alguna persona Eclesiástica, porque aunque es verdad que suele vestir sotana, pero es como el P. Hacha en México y Chepe Pó en Querétaro, quien de pocos días a esta parte se nos presenta con una turca venerable. * En fin, es de aquellos acólitos por necesidad, como el Sacristán de mi tierra que, aunque lo vemos con su roquete almidonado, es tan clérigo como los Santones de la Turquía. (Esta nota es de Navarrete, y aunque se imprimió está variada en parte.)

(5) Esta sátira se escribió (el Retrato del Domine Suás) (T. II, 160) contra dicho Suasnávar, que provocó con algunos versajos al autor, después se ordenó hasta de Sacerdote; toda su vida la gastó en ensuciar papel y jamás hizo un verso que mereciera este nombre. Murió en $1^{\circ}$ de junio de 1811.

(8) Tio Ballesteros (II, 168). Este era un anciano faceto, que a los que se lo mandaban, cantaba una cantadilla de su tiempo que llamaba la Hueva Elena [sic]: (se la ví en mi casa en la Real Fábrica de cigarros). Murió.

(9) También se habla en la sátira de Chepito el Músico, o Mr. Chepit como le decía el satírico Tresguerras. Llamábase José Alberto Gon-

- La palabra "turca" está registrada en los diccionarios solamente como "borrachera". Sin embargo, fue usada, cuando menos desde el siglo xvit, significando una vestidura eclesiástica. En el Diario de Antonio de Robles se lee el 8 de julio de 1682: "Estos días entró en México un canónigo de Babilonia (1), que viene del Perú, don Elias de San Juan, vestido con sotana de seda y con cuello blanco, con turca sobre ropa" (Ed. Porrúa, 1946, tomo II, pp. 21-22) . A principios del siglo xvirr, en el libro: Dechado de Principes Eclesiásticos... de fray Miguel de Torres, impreso en Puebla, que es una biografía del obispo Manuel Fernández de Santa Cruz, se lee: "El vestide exterior era una sotana y turca de lanilla, nada prima en el tejido y ésta remendaba su propia mano muchas veces por excusar el gasto..." (fol. 377). Parece ser, pues, una esclavina o muceta. También, a fines del siglo pasado se llamó así a un saco o abrigo parecido al caftán turco de muchos botones. 
zález, Tambor Mayor y Maestro de Músicos del Regimiento de esta ciudad; poseía bastante habilidad músical y era algo afeminado en movimientos \& $\mathbf{a}^{\mathrm{a}}$.

(10) En la misma Sátira, octava 15, estas expresiones: cartabones, medidas, parecen hacer alusión a haberse criado Mr. Chepit con un Maestro Zapatero, que era reputado por su Padre, aunque parece no haberlo sido (Chepito murió pasado por las armas por las tropas del Rey en San Miguel el Grande, en 812 o 13, me parece que por Orrantia).

(18) Suasnávar no era congregante; está enterrado en San Antonio; estuvo encargado del curato de Ixtla al principio de la insurrección y antes de ordenarse habia estado de Escribiente en casa de Domínguez. Chepito el Músico picaba de Arquitecto, dibujante $\&^{\cdot a}$ pero de nada entendía, o "Arquitete", esto es, "que nada sabe y en todo se mete" como le había puesto Tres-guerras. $\AA$ éste y a Romero los retrató al natural de figurones muy ridículos dicho Tres-guerras en un Libro que he visto y posee en el día el Lic. Sotelo. A Suasnávar me parece no se atrevió por haberse ordenado. Ramón el Zocato era un hombre muy ordinario saragate completo, de Celaya muy fandanguero y contemporáneo de Quirino el Mosquito, muy mentado en su tiempo. Romero tenía mucho talento y salió bastante aprovechado en el $1^{\circ}$ curso del P. Pardo, quien aunque en su vejamen lo rajó muy bien, tal vez sería por alguna picardía que le jugó o una de las muchas candideces de mi Padrino; también aprovechó no poco en México en las Matemáticas según alli me lo aseguraron.

Con esto quedan resueltas, en parte, las dudas de la página 21 del Prólogo a los Ocios. Respecto del padre fray Francisco Soria, citado por Tresguerras en la página 159 , podemos añadir que publicó un libro que fue el Acto / de Filosofía Natural, / que se ha de tener publicamente / en el Convento de Nuestro / S.P.S. Francisco / de Zacatecas / Dedicalo / a su amada Madre de Santa Provincia / de los Zacatecas / el P. Lector de Artes Fr. Carlos / Fraga. / Lo sustentaba / Fr. Francisco Soria / Estudiante de dicha Facultad / el dia 7 de Agosto de 1806. / Con las licencias necesarias. / Impreso en Guadalaxara en la Oficina de Don Ma! riano Valdés Tellez Girón, Año de 1806.1

1 La portada del libro y un párrafo fueron publicados en Novedades, Suplemento Cultural, 31 de septiembre de 1962. 
DOI: http://dx.doi.org/10.22201/iie.18703062e.1963.32.754

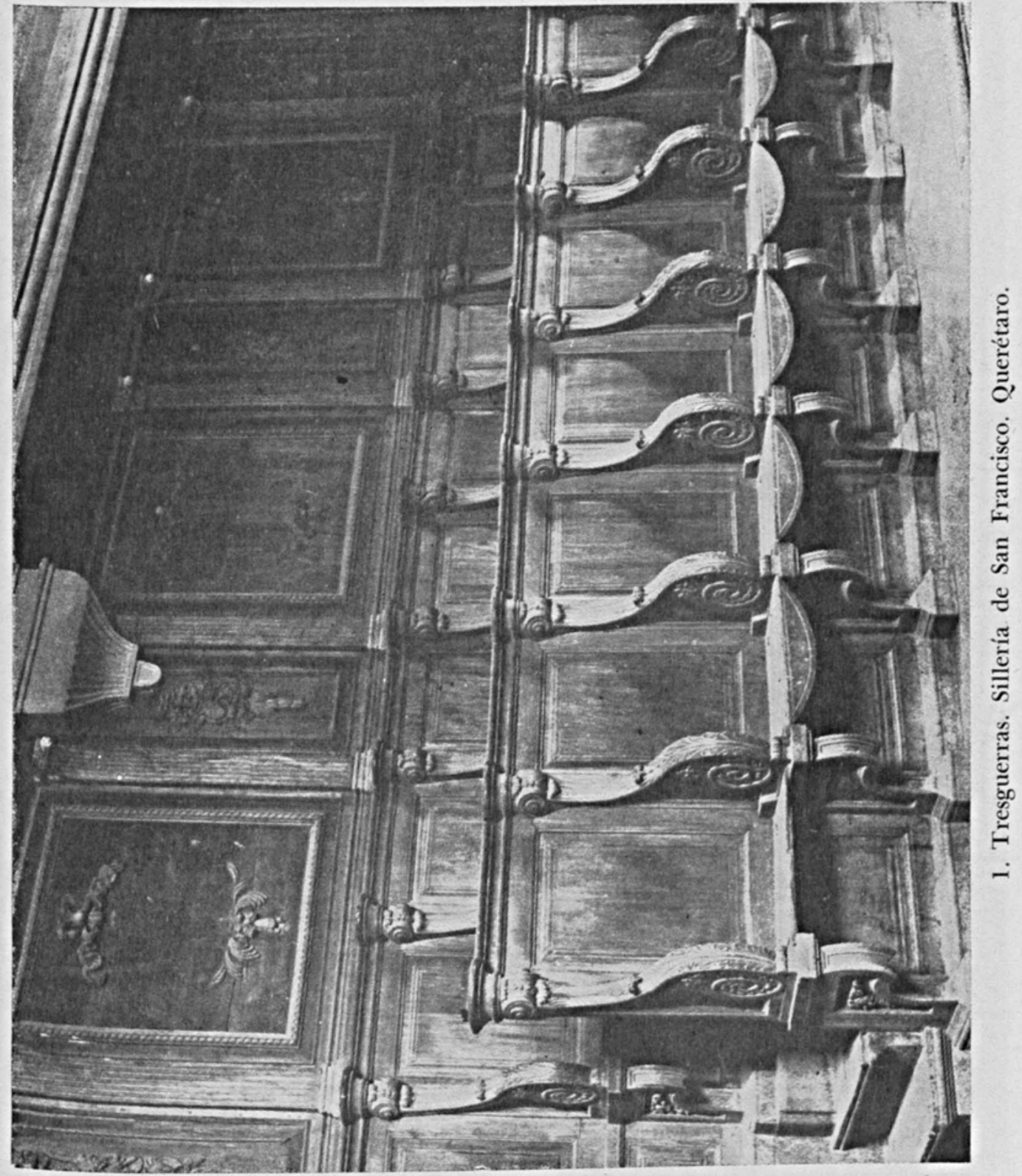


DOI: http://dx.doi.org/10.22201/iie.18703062e.1963.32.754

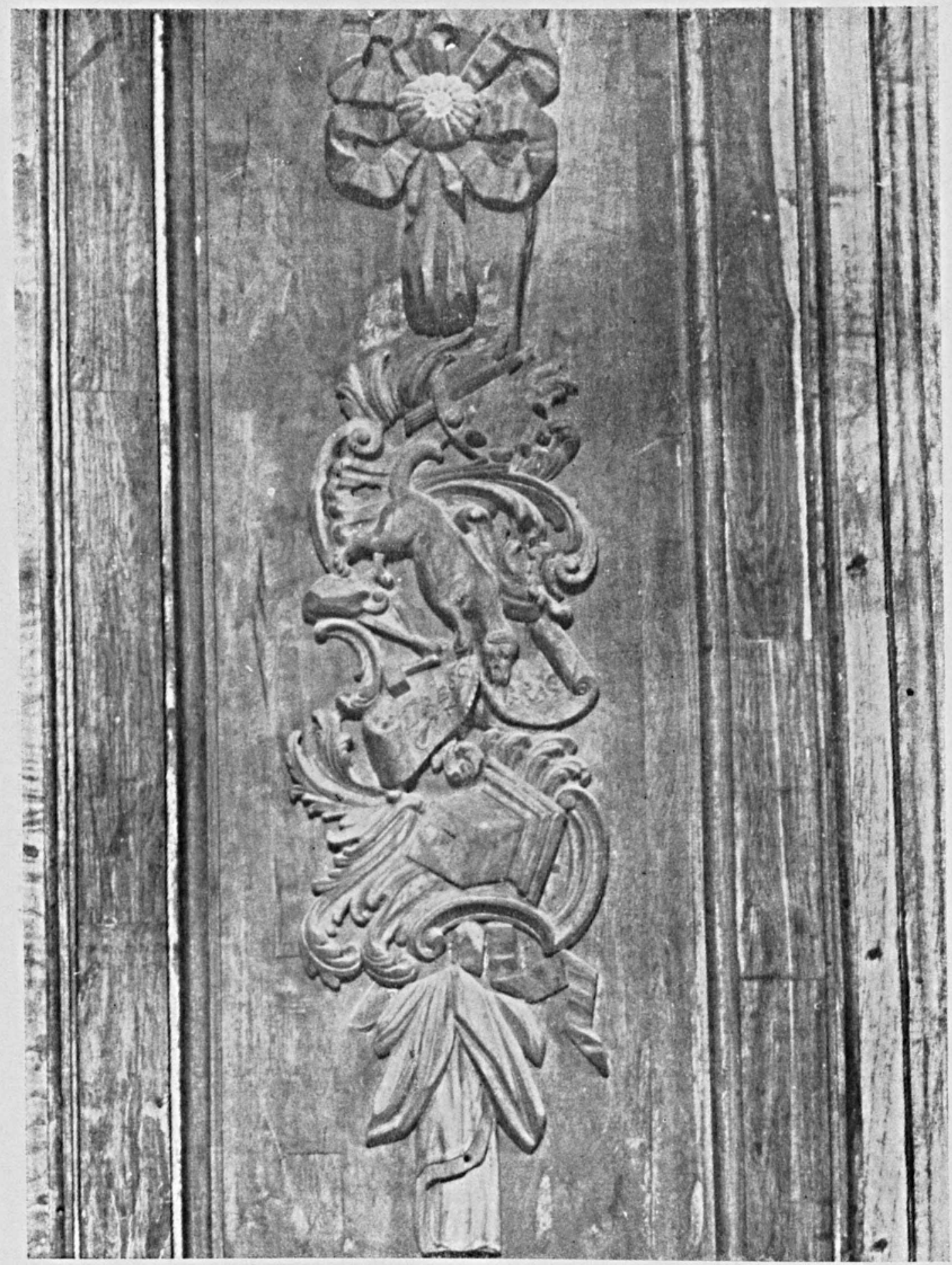

2. Sillería de San Francisco. (Detalle) Querétaro. 
DOI: http://dx.doi.org/10.22201/iie.18703062e.1963.32.754

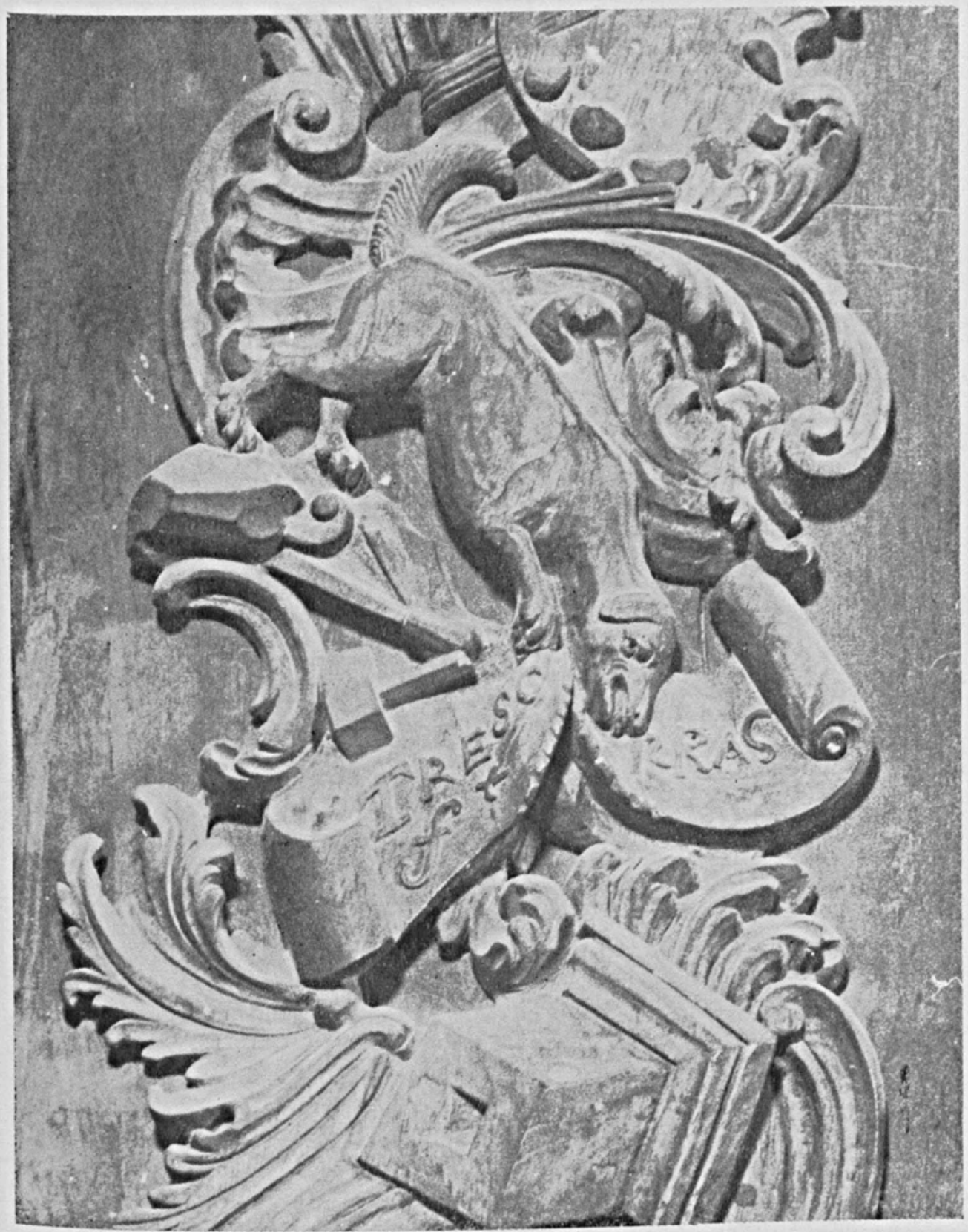

3. Sillería de San Fraacisco. Querétaro. Relieve con la firma de Tresguerras. 
DOI: http://dx:doi.org/10.22201/iie.18703062e.1963.32.754

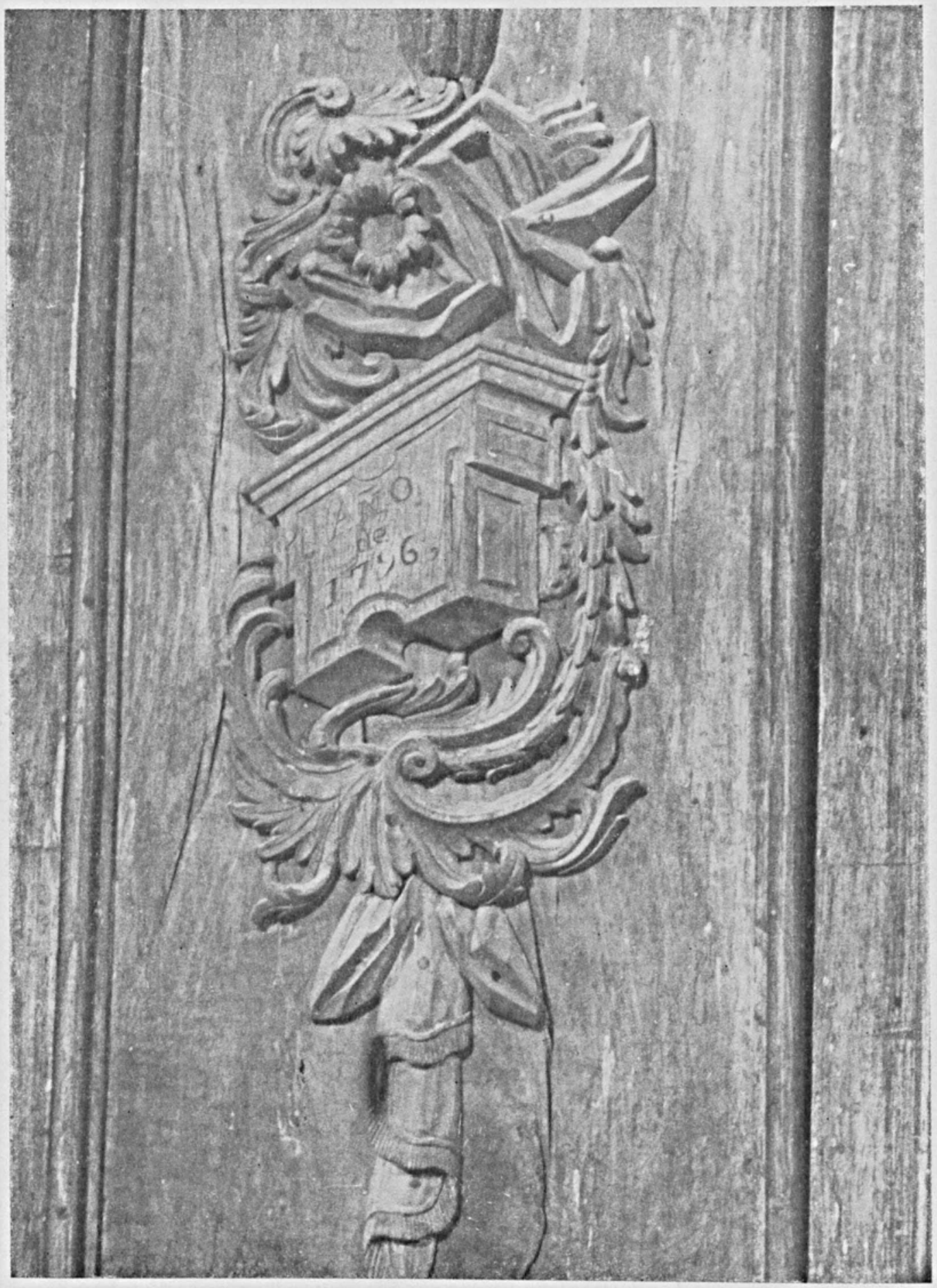

4. Sillería de San Francisco. Querétaro. Relieve con la fecha. 
DOI: http://dx.doi.org/10.22201/iie.18703062e.1963.32.754

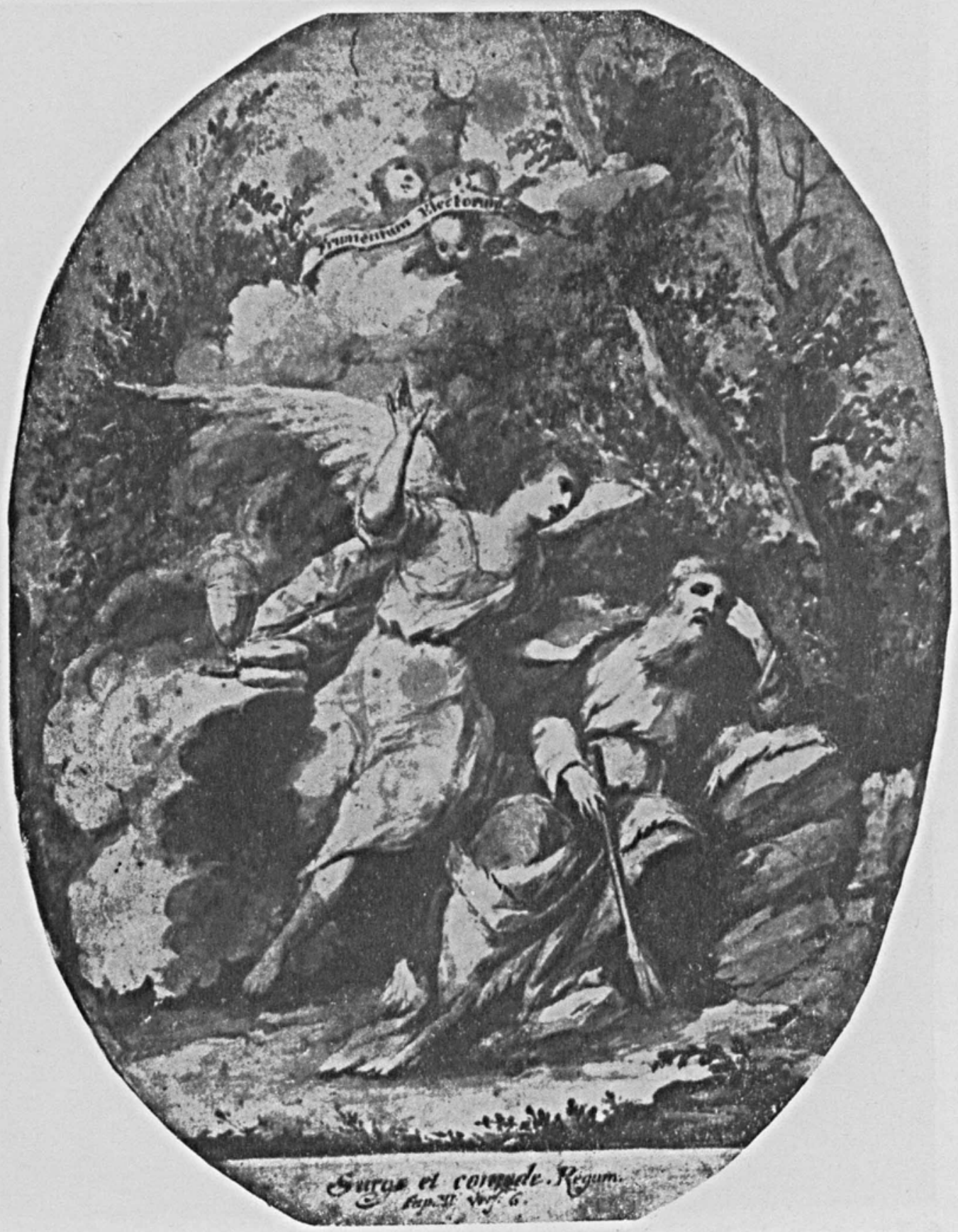

5. Tresguerras. San Elias. Acuarela. Museo de Pintura Colonial de San Diego. 
DOI: http://dx.doi.org/10.22201/iie.18703062e.1963.32.754

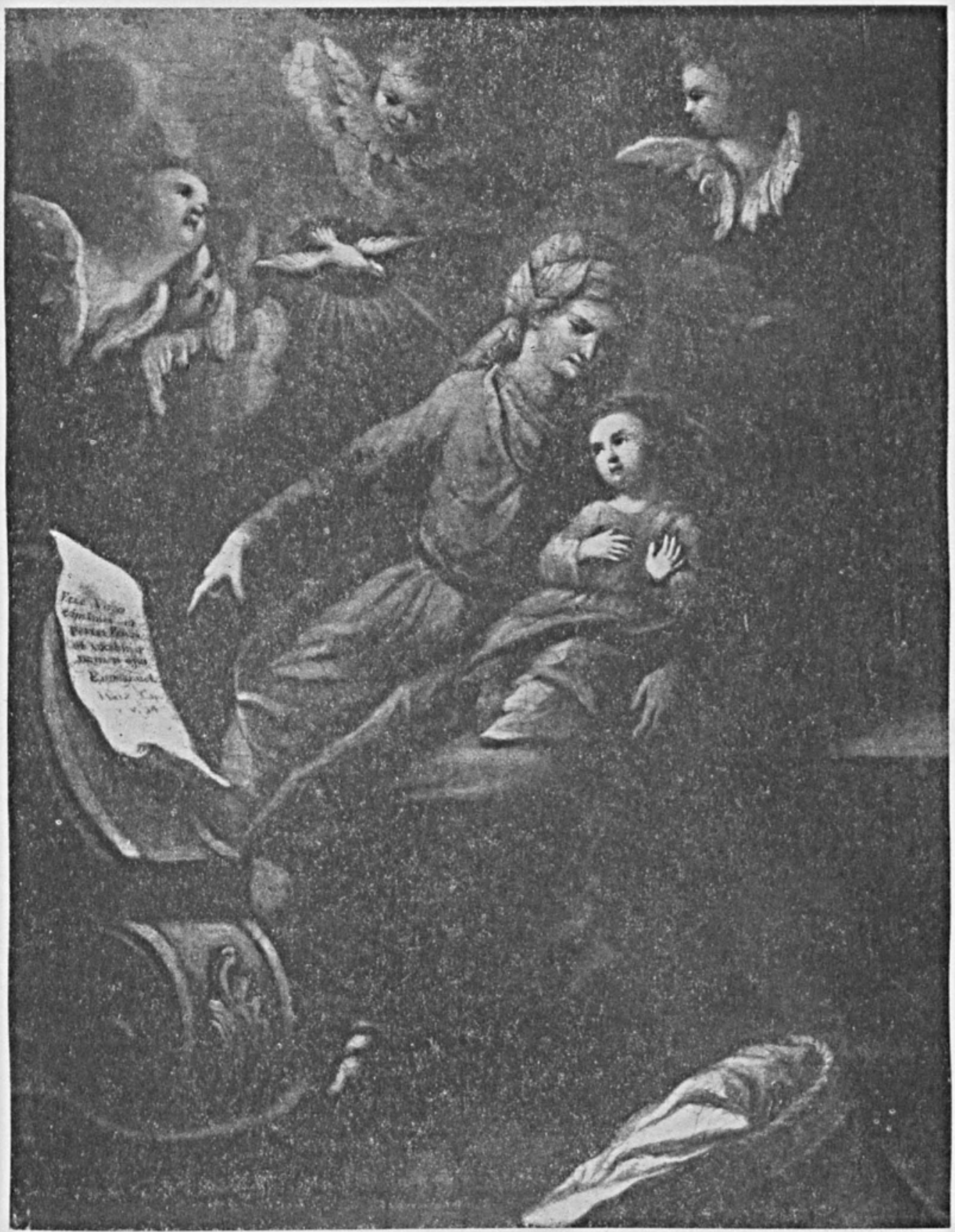

6. Tresguerras. La Premonición de Santa Ana. Museo de Pintura Colonial de S. Diego 


\section{Otra acuarela de Tresguerras}

En una visita a las bodegas del INBA, en la Ciudadela, en compañía del Sr. Horacio Flores-Sánchez, Jefe del Departamento de Artes Plásticas, encontré, perdido entre docenas de mediocridades y basuras pictóricas, un precioso óvalo, a la acuarela, firmado por Tresguerras. Ignoro cuando fue a dar a las antiguas Galerías de San Carlos y ningún catálogo lo consigna.

Representa la acuarela el momento en que Elías, huyendo de Jezabel, llegó a Berseba, donde, fatigado "sentóse bajo una mata de retama y deseó morir". Quedóse dormido y "he aquí que un ángel le tocó el hombro diciéndole: Levántate y come. Miró Elías y vio junto a sí una torta cocida y una vasija de agua. Comió y bebió y luego volvió a acostarse, pero el ángel de Jehová vino por segunda vez y le tocó diciéndolc: Levántate y come, porque te queda todavía mucho camino". 2

Tresguerras hace que el viejo profeta, sin abandonar su flamígera espada, que sostiene con su mano derecha contra el suelo, se recline sobre unas piedras y duerma. El ángel, que apenas toca el suelo con su pie izquierdo, mantiene el vuelo mientras toca el hombro de Elías. A la izquierda, en una nube, están dos tortas a la usanza de las que desayunaba Tresguerras y una copa con tapadera. Arriba, el símbolo; tres cabecitas de serafines sostienen el cáliz con la Forma Eucarística. En una filacteria dice Frumentum electorum, "trigo de los elegidos". En la parte inferior derecha, la firma: $3 \mathrm{G}$. fecit. Mide el óvalo $30 \times 23 \mathrm{cms}$.

Esta pequeña obra de arte, ahora del Museo de Pintura Colonial es, sin duda, de lo mejor que produjo en pintura el inquieto Tresguerras.

Aprovecho esta nota para publicar, con un breve comentario, otra pintura de Tresguerras, del mismo Museo. Es el pequeño oleo que ha sido llamado Infancia de la Virgen, o La Educación de la Virgen, o Santa Ana enseñando a leer a la Virgen. No es ninguna de las tres cosas.

Adelanto que esta pintura es una de las fundadoras de las Galerías de San Carlos (hoy Museo de Pintura Colonial de San Diego) pues su creador, el benemérito don José Bernardo Couto, lo regaló para ellas. Dice en su Diálogo:

"Pesado: Acabas de pronunciar el nombre de Tresguerras y veo ahí un cuadrito de su mano que me parece representar la Infancia de la Virgen." "Couto: Presente que me hizo mi bondadoso amigo el licenciado don Víctor Covarrubias y que creí deber colocar en esta galería más bien

2 I Reyes, cap. 19, vers., 1.7. 
que en mi casa. No puede tomarse sino como un juego de pincel, muestra de su afición a la pintura, que fue su primer amor y que nunca pudo poner en olvido, si bien tuvo que aplicarse totalmente a la arquitectura." 1

Está Santa Ana sentada con la Virgen niña en su regazo. Santa Ana apunta con su mano derecha hacia un papel que pende de una especie de ménsula o pata de una mesa gigantesca. En el papel dice: Ecce Virgo concipiet et pariet Filium et vocabitur nomen ejus Emmanuel, Isaia [sic], cap. 7, v. 14. Pero, en realidad, es el texto de San Mateo, cap. I, vers. 23: "He aquí que una Virgen concebirá y parirá un Hijo y le pondrá por nombre Emmanuel."

El Espiritu Santo revuela a la derecha de la santa, acompañado de cuatro serafines. En el rincón derecho una labor de costura en una canastilla de la que asoman unas tijeras.

No es el tema, como se ha visto, ninguna educación de la Virgen. Es el anuncio de Santa Ana de la maternidad divina de María. Su nombre correcto es La Premonición de Santa Ana.

$\mathrm{Y}$ jamás volveré a dejarme atrapar por don Francisco Eduardo Tresguerras. Es decir, que sean otros los que caigan en sus redes.

1 Dialogo sobre la historia de la pintura en México. Segunda edición, preparada por Manuel Toussaint, F. C. E. México, 1947, p. 126. 